
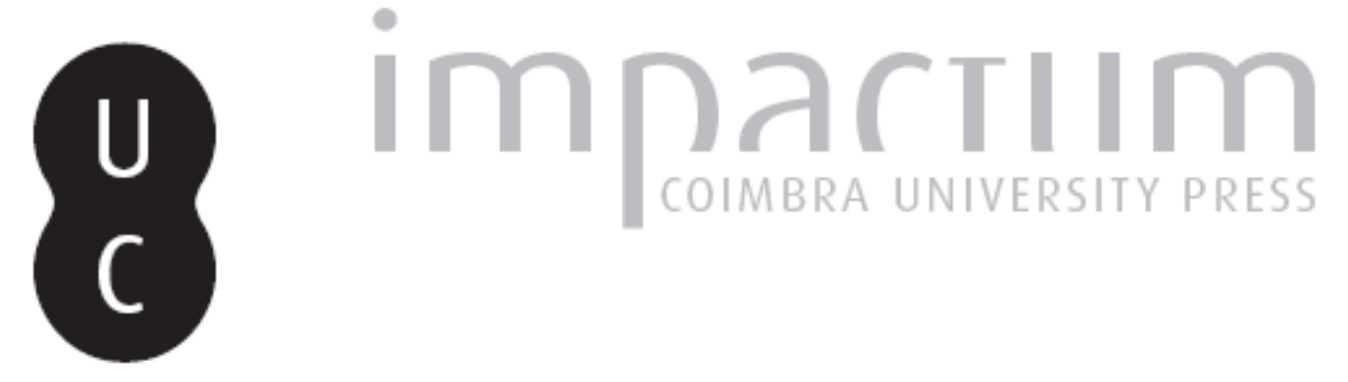

\title{
As duas faces do mal: comunismo e nazismo
}

Autor(es): $\quad$ Vicente, José João Neves Barbosa

Publicado por: $\begin{aligned} & \text { Universidade Católica de Petrópolis; Instituto Brasileiro de Informação } \\ & \text { em Ciência e Tecnologia }\end{aligned}$

URL

persistente:

URI:http://hdl.handle.net/10316.2/33024

DOI:

DOI:http://dx.doi.org/10.14195/1984-6754_4-1_4

Accessed : $\quad$ 26-Apr-2023 09:06:29

A navegação consulta e descarregamento dos títulos inseridos nas Bibliotecas Digitais UC Digitalis, UC Pombalina e UC Impactum, pressupõem a aceitação plena e sem reservas dos Termos e Condições de Uso destas Bibliotecas Digitais, disponíveis em https://digitalis.uc.pt/pt-pt/termos.

Conforme exposto nos referidos Termos e Condições de Uso, o descarregamento de títulos de acesso restrito requer uma licença válida de autorização devendo o utilizador aceder ao(s) documento(s) a partir de um endereço de IP da instituição detentora da supramencionada licença.

Ao utilizador é apenas permitido o descarregamento para uso pessoal, pelo que o emprego do(s) título(s) descarregado(s) para outro fim, designadamente comercial, carece de autorização do respetivo autor ou editor da obra.

Na medida em que todas as obras da UC Digitalis se encontram protegidas pelo Código do Direito de Autor e Direitos Conexos e demais legislação aplicável, toda a cópia, parcial ou total, deste documento, nos casos em que é legalmente admitida, deverá conter ou fazer-se acompanhar por este aviso.

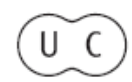



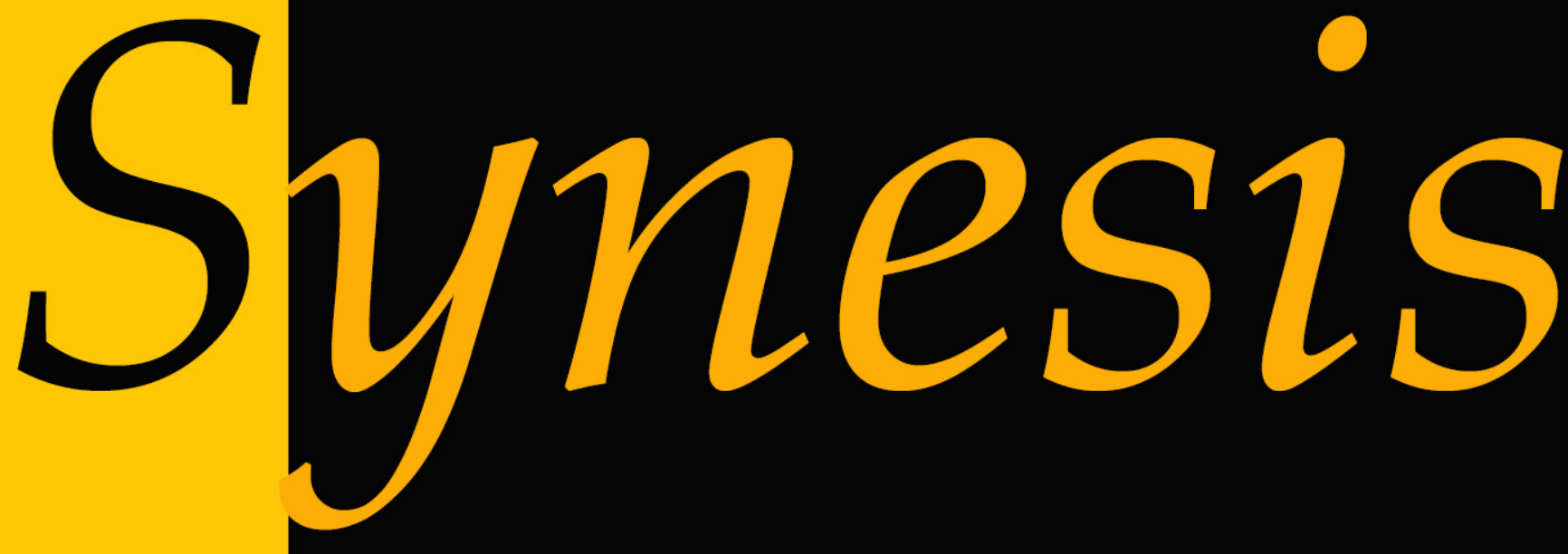

Revista do Centro de Teologia e Humanidades ISSN 1984-6754

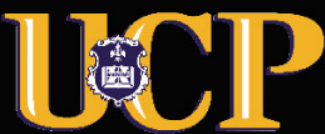




\title{
As DUAS FACES DO MAL: COMUNISMO E NAZISMO ${ }^{1}$
}

\author{
José João Neves Barbosa Vicente ${ }^{2}$
}

Resumo: em Origens do totalitarismo, publicada em 1951, Arendt pensa o grande mal do século XX: o fenômeno totalitário como destruição da pluralidade humana, negação da semelhança dos homens e da sua pertença a uma mesma humanidade. Esse mal, para ela, reduz-se a dois regimes: o nazismo de Hitler e o comunismo de Stalin. A proposta deste artigo é analisar as características comuns entre esses dois regimes como descritas por Arendt

Palavras - chave: Totalitarismo; Pluralidade; Liberdade; Ideologias; Campos de concentração.

Abstract: In The origins of totalitarianism, published in 1951, Arendt thinks the great evil of $20^{\text {th }}$ century: the totalitarian phenomenon as destruction of the human plurality, negation of the similarity of the men and they belong to the same humanity. This evil, for she is reduced to two regimes: the Nazism of Hitler and the communism of Stalin. The proposal of this paper is to analyze the common characteristics between these two regimes as described by Arendt.

Keywords: Totalitarianism; Plurality; Freedom; Ideologies; Concentration camps.

\footnotetext{
1 Artigo recebido em 30/01/2012 e aprovado para publicação pelo Conselho Editorial em 10/06/2012.

2 Professor Assistente da Universidade Federal do Recôncavo da Bahia. Doutorando em Filosofia pela Universidade

Federal da Bahia. Currículo Lattes: http://lattes.cnpq.br/3698270800560619. E-mail: josebvicente@gmail.com.
} 


\section{Introdução}

Para Arendt, a política "baseia-se na pluralidade dos homens. (...) trata da convivência entre diferentes" (ARENDT, 2002, p.21). Assim, os regimes totalitários: o nazismo de Hitler e o comunismo de Stalin representam, para ela, a destruição da política porque destroem a pluralidade dos homens ao pressioná-los "uns contra os outros", destruindo assim, "o espaço entre eles". Negam, também, a pessoa como tal, na sua diferença com todos os outros, ao dissolver a sua pluralidade “em Um-Só-Homem de dimensões gigantescas" (ARENDT, 1989, p.518).

Esses regimes, ao contrário das ditaduras ou tiranias clássicas, instalam-se de forma legal e contam com apoio das massas. Ao coromperem todas as relações e todas as solidariedades, eles não destroem apenas a vida política, mas, também, a vida privada. Com o nazismo e o comunismo, a pessoa humana não consegue coexistir: eles não isolam simplesmente os indivíduos como faziam as tiranias, os privam de todas as relações com os seus próximos e consigo mesmos através da ideologia, “a lógica de uma ideia” (ARENDT, 1989, p.521): superioridade de uma raça para o nazismo e revolução proletária para o comunismo; do terror, cujo objetivo é impossibilitar toda a resistência e toda a ação; da inutilidade dos indivíduos, criando neles um sentimento de "não pertencer ao mundo de forma alguma" (ARENDT, 1989, p.528).

Para facilitar a exposição do tema em questão, além da introdução e considerações finais, o texto encontra-se dividido em cinco tópicos: metas e práticas; fundamentos das doutrinas; a "transformação da natureza humana"; o "mal radical" e a compreensão da novidade. Em cada um desses tópicos estão, respectivamente, as discussões sobre as técnicas utilizadas pelo nazismo e comunismo para atingirem seus objetivos; a concepção do homem sobre a qual eles se baseiam; suas preocupações com a imprevisibilidade humana; as práticas criminosas imperdoáveis e impuníveis e o esforço para compreender algo inédito e sem precedentes que destruiu os conceitos e categorias da tradição do pensamento ocidental.

\section{Metas e práticas}

São regimes que traçam como objetivo chegar a uma "sociedade perfeita", através da destruição dos "elementos negativos" que se opõem a ela. Mas, pretendem, também, ser filantrópicos, eles querem o bem: do povo alemão, desejo do nazismo e de toda a humanidade, 
desejo do comunismo. Para isso, ambos se dão "o direito - e mesmo o dever - de matar" (BESANÇON, 2000, p.9), cortando, assim, todas as "raízes espirituais", para realizarem suas autonomias em relação a toda força posta acima deles. Eles são, também, seus próprios princípios: comparecem somente perante seus próprios tribunais, sendo ao mesmo tempo juízes, testemunhas e acusados.

Para o nazismo, é necessário construir, através de qualquer meio, um regime novo e um outro homem; simetricamente, para o comunismo, é necessário colocar em prática a destruição da pseudoclasse: ambos pertencem, portanto, ao mesmo mal, o totalitarismo, "um movimento de dissolução política da civilização europeia” (FURET, 1995, p.244), ou melhor, um movimento de destruição da pluralidade humana, algo que está na base de toda a política autêntica, "a condição da ação humana pelo fato de sermos todos os mesmos, isto é, humanos, sem que ninguém seja exatamente igual a qualquer pessoa que tenha existido, exista ou venha a existir" (ARENDT, 2009, p.16).

Os dois regimes compartilham, com efeito, o mesmo modo de funcionamento totalitário: sozinhos dominam o Estado, a sociedade civil, as igrejas, o sistema econômico, a vida social, e consideram o cidadão um indivíduo fundido na massa que comunga coletivamente no culto ao Chefe que representa o auge do aparato totalitário, a típica encarnação do principio de dominação, que obriga o outro a se submeter, a "aniquilar-se", e na obediência sem reservas ao partido. Fora do partido, que encarna sozinho o Estado, existe simplesmente o inimigo de raça o judeu para um e o inimigo de classe - o burguês para o outro, contra os quais se cristalizam o ódio que forma o cimento das massas populares.

A marca fundamental do nazismo e do comunismo é a violência. Não apenas caminham no sentido da própria violência interna ao indivíduo, que eles exaltam e justificam, mas mantêm também um sentimento comunitário difuso, eufórico, segurador, que se solidifica na exclusão e eliminação dos "parasitas" e "inimigos". Dirigem uma boa parte da violência coletiva em direção ao exterior, levando uma política excessivamente belicosa que se traduz por atos selvagens de agressão, invasão, anexações e ocupações homicidas que apenas dão uma pequena ideia, entre as inumeráveis atrocidades perpetradas. São regimes que necessitam multiplicar massacres e extermínios, exacerbar o terror num movimento de aceleração que parece só poder desaguar no apocalipse ou no caos. São formas de governos “cuja essência é o terror e cujo princípio de ação é a lógica do pensamento ideológico" (ARENDT, 1989, p.526). Uma mistura, de acordo com Arendt, nunca antes usada nas várias formas de domínio político.

O comunismo não escraviza, não deporta e nem executa em nome da força e da raça, 
essas ações fazem parte da prática do nazismo. O comunismo escraviza, deporta e executa em nome do conceito e da classe. Assim, no seu "princípio ético", se ainda é possível falar em ética, não existe diferença entre esses dois regimes. Ambos repousam sobre uma necessidade: arrancar todas as raízes da ordem existente destruir-lhes os fundamentos. Para o comunismo é preciso arrasar todos os sustentáculos do mundo antigo para construir o novo; para o nazismo é preciso um novo mundo embelezado pelos conceitos arianos e para conseguir isso, a sujeira representada pelos judeus devem ser eliminada. Portanto, os dois regimes se fundamentam de maneira similar numa falsa concepção de homem, geradora de crimes contra a humanidade que não foram apenas da ordem da ideia.

\section{Fundamento das doutrinas}

As doutrinas do materialismo biológico - no nazismo e do materialismo histórico - no comunismo estão pautadas na concepção do homem que se pode definir como materialismo do sujeito. Tanto no um quanto no outro, o homem encontra-se fixado ao sujeito material segundo as determinações do sujeito classe e do sujeito raça, não podendo nenhum dos dois escapar à lei histórica ou à lei biológica que os encerra em sua interioridade de massa. Isso significa dizer que ninguém pode renegar sua hereditariedade social ou sua hereditariedade racial a partir do momento em que a ideologia, disfarçada de "ciência proletária" ou de "ciência ariana" fixa o sujeito ao seu fundo material.

O homem fixo nunca está livre para falar. Quando toma a palavra, por intermédio dele fala o ariano ou o judeu, é o proletariado ou o burguês que se exprime, é o partido nazista ou o partido comunista que ordena. O sujeito-classe ou o sujeito-raça se coloca de imediato no centro do mundo, sendo este último apenas a dilatação social ou racial do sujeito monódico, não existe mais nenhuma exterioridade conhecida como tal. A verdadeira vida não está alhures, à distância de um sopro, mas na imanência da raça e da classe que sepulta cada um em si mesmo. O comunismo e o nazismo, com a mesma face de medusa, representam as duas figuras da petrificação, as duas faces do mesmo mal, na expressão de Arendt, o totalitarismo.

Reduzir o ser humano concreto a um material social ou racial, quer dizer, a um sujeito formal definido por meio de processos sociais ou raciais, como fazem o nazismo e comunismo, significa destruir sua realidade substancial, o mesmo que sua humanidade. Eles envenenam, em cada criatura humana, o "homem de dentro". Propõem acabar com a alma, a velha alma fora de 
moda: matar homens reais em nome de um ideal abstrato de humanidade, negando a certos homens o direito de serem homens. Aniquilam todo e qualquer espaço para a manifestação de uma liberdade individual ou tradição cultural, mesmo a religiosa; destroem todo o tipo de ação autônoma dos atores sociais; devoram a sociedade civil, arrancam o indivíduo de seu meio, local ou religioso e o mobiliza ao serviço do Estado. Transformam a sociedade numa multidão de massa dócil à palavra e às ordens de um chefe e eliminam todos os espaços públicos onde se debatem as escolhas.

Negam as leis positivas e obedecem "inequivocamente àquelas leis da Natureza ou da História que sempre acreditamos serem a origem de todas as leis" (ARENDT, 1989, p.513). Substituem, assim, o Estado de direito pela lei de movimento perpétuo; substituem a realidade pela ideologia que, no fundo, é a expressão da vontade do chefe e despreza totalmente os fatos e as opiniões, mesmo que esses fatos ou opiniões representem milhões de indivíduos. A ideologia é para o nazismo e o comunismo um poderoso instrumento capaz de explicar absolutamente e de maneira total o curso da história: "os segredos do passado, as complexidades do presente, as incertezas do futuro" (ARENDT, 1989, p.521). Ela é mobilizada cuidadosamente, para que ninguém jamais comece a pensar, ou pelo menos, para que o pensamento dos indivíduos torne “impotente, irrelevante e sem influência para o sucesso ou fracasso do poder” (BAUMAN, 2000, p.94). Ela arruína, portanto, todas as relações com a realidade e constrói um mundo fictício e logicamente coerente. O nazismo e o comunismo Atacam também a pluralidade exigindo a unanimidade sem qualquer tipo de debate de opiniões.

\section{A "transformação da natureza humana"}

O apogeu desses regimes acontece nos campos de concentração, suas instituições centrais: assassinam a dignidade humana e apagam a distinção entre vítimas e carrascos, matam, em cada pessoa, a estima que tem por si mesma, destroem a sua identidade e o seu caráter único, com o intuito de acabar com a sua capacidade para pensar, agir e começar qualquer coisa por ela mesma.

Assim, o grande inimigo do nazismo e do comunismo não é o mundo exterior, mas "a imprevisibilidade que advém do fato de que os homens são criativos, de que podem produzir algo novo que ninguém jamais previu" (ARENDT, 1989, p.509-510). O poder total almejado por esses regimes necessitam de um mundo de reflexos condicionados, por isso, o objetivo supremo, para eles, não é “a transformação do mundo exterior ou a transformação revolucionária da 
sociedade, mas a transformação da própria natureza humana” (ARENDT, 1989, p.510). Natureza entendida por Arendt, como "condição" que pode sempre ver-se alienada, se não for reconhecida e garantida pela instituição jurídica e política da sociedade.

Por isso, para ela, as profecias provenientes de um mundo que, provavelmente, vivia em segurança, se enganaram tragicamente. Pois, elas supõem uma natureza humana imutável através dos tempos e identificam essa natureza com a história. Assim declaram que um a ideia de um domínio total não é apenas desumano, mas irrealista. No entanto, "de lá para cá, aprendemos que o poder do homem é tão grande que ele realmente pode vir a ser o que o homem desejar" (ARENDT, 1989, p.507).

Para Arendt, as propriedades que são tradicionalmente atribuídas ao homem, tão logo desaparecem sob condições nazistas e comunistas; assim, fica evidente de que elas não dependem de uma natureza imutável. A chamada "natureza humana" é, na verdade, "moldável e se adapta a uma gama muito extensa de compreensão" (SARTTORI, 1981, p.140). O que a democracia, por exemplo, não consegue dos seus cidadãos, os regimes nazistas e comunistas conseguem dos seus súditos; aquilo que parece ser inconcebível para uma pessoa suportar, em condições normais, é suportado nos campos de concentração.

Para o nazismo e comunismo, nos campos de concentração é "possível fazer tudo o que se quiser com o homem" (FREYER, 1965, p.149), inclusive destruí-lo a qualquer momento como se fosse mosquito. Assim, para Arendt, no lugar de "natureza humana" deve-se falar de “condição humana", uma expressão política que não deve ser interpretada em termos metafísicos, como se as atividades que nela se realizam devessem se realizar de uma forma única e para todo o sempre. A condição humana manifesta nas suas ações, palavras, pensamentos e obras. É construída e garantida a partir de artifícios convencionais, como a legalidade, a cidadania, o respeito à pluralidade humana e a posse garantida de um lugar próprio e de uma ocupação social, condições artificiais sem as quais não subsiste a dignidade da existência humana.

Para Baudouin (2000, p.171), apesar de não terem inventado a crueldade, o massacre coletivo, o genocídio e não serem os primeiros a imaginarem a instituição dos campos, os regimes nazistas e comunistas conferiram-lhes uma significação sem precedentes na história, administrando a prova da superfluidez do homem. São nesses campos que eles conseguem obter seus "cidadãos" perfeitos e ideais de reflexos puramente condicionados, capazes de lealdade total, irrestrita, incondicional e inalterável. Cidadãos prontos para não obedecerem a "nenhum outro princípio organizador a não ser o Estado, encarnado na pessoa do chefe" (RICOEUR, 1995, p.151). Ou melhor, "horríveis marionetes com rostos de homem, todos com o mesmo 
comportamento do cão de Pavlov, todos reagindo com perfeita previsibilidade mesmo quando marcham para a morte" (ARENDT, 1989, p.506).

O processo de mudança ou transformação do homem se dá em três tempos: mata-se a pessoa jurídica, mata-se a pessoa moral e mata-se a individualidade. A morte da pessoa jurídica está associada à produção de apátrida. O nazismo e o comunismo privam os homens de seus direitos, e lhes transformam em "fora - da - lei”, mesmo estando em seus próprios países. Assim, ao torturá-los nos campos de concentração ou mesmo matá-los, esses regimes lidam com “pessoas" cuja existência não é reconhecida por nenhuma lei: do ponto de vista jurídico, o castigo ou o homicídio pura e simplesmente não acontece; a morte da pessoa moral significa tornar a morte anônima, ou sem qualquer significado quer para os parentes, quer para conhecidos e amigos, através da interdição de toda e qualquer solidariedade, todo e qualquer protesto e da eliminação da linha de demarcação entre vítimas e carrascos; a morte da individualidade ou a morte psíquica significa a destruição da espontaneidade e a transformação dos indivíduos em "feixes de reações".

\section{O "mal radical"}

Ao provarem que qualquer ato, por mais inimaginavelmente horripilante que fosse considerado até então, lhes eram possível, o nazismo e o comunismo nos colocaram diante do "mal radical" - crime imperdoável e impunível: impossível de ser explicado, por exemplo, pelos "maus motivos do interesse pessoal, avareza, cobiça, ressentimento, desejo pelo poder e covardia (...) o ódio não podia vergar, o amor não podia suportar e a amizade não podia perdoar" (ARENDT, 1989, p.510).

Imperdoável porque mesmo para o perdão há limites. Ele é algo que somente as vítimas podem conceder. É também o que somente elas podem recusar. Ninguém pode decretar em seu lugar que determinado crime monstruoso deve um dia ser perdoado pelos parentes próximos das vítimas ou por aqueles que se salvaram do terror. Ninguém tem o controle do tempo do sofrimento e do tempo do luto. Impunível porque o mais alto grau de condenação, a pena de morte, é irrisório face à amplitude do mal realizado. Com o enforcamento de Eichmann, por exemplo, o mal não foi reparado. E mais, esse mal cometido, é inteiramente desconhecido pelos nossos aparatos jurídicos - ele está acima de qualquer tipo de legalidade humana; o direito está absolutamente incapaz de aplicar uma pena que seja proporcional ao mal cometido sem se tornar ele próprio inumano, ou seja, sem se autodestruir. 
Esse mal, tornado possível pelo nazismo e pelo comunismo nos campos de concentração, não pode ser compreendido no sentido geral, como simplesmente algo negativo, nocivo e prejudicial a alguém. Não pode ser compreendido como imperfeição, sofrimento ou pecado. Portanto, não é o mal, que, Plotino, definiu como "a privação do bem" e que os escolásticos precisaram: a privação de um bem devido. A cegueira, por exemplo, é um mal, porque faz parte do homem o direito de ver. Se ele é incapaz de ver o invisível, apesar de ter bons olhos, ele não pode se lamentar, pois a vista não é feita para ver as coisas mais além de um campo limitado. A ideia é então de que o mal se define negativamente. Ele é puro nada, um vazio no ser. Esse mal, também, não é o mal que, como pensava Kant, se encontrava enraizado, por exemplo, nas profundezas insondáveis da alma humana.

O horror que se apoderou das pessoas diante do que o nazismo e o comunismo thes infligiram, de acordo com Arendt (1989, p.510), é radical, precisamente, por não possuir raízes na interioridade do sujeito; ele é radical porque deixou de estar limitado pelas motivações ou tendências naturais em que se enraíza, segundo a compreensão kantiana, por exemplo. O mal, portanto, é concebido por Arendt, como tendo sua origem numa ausência, a ausência de pensamento. Esta é uma posição absolutamente desconhecida e inimaginável quer por Agostinho quer por Kant, os dois pensadores mais admirados por ela.

O exemplo mais emblemático dado por Arendt está na pessoa de Adolf Eichmann, um antigo diretor do escritório IV-B-4 da Secretaria Central de Segurança do Reich. O burocrata que metodicamente coordenava horários ferroviários para enviar os elementos indesejáveis aos campos de extermínio. Um homem que não era estúpido e muito menos, "fraco de memória", porém, "incapaz de discernir o certo do errado" (ARENDT, 1999, p.42); um homem disposto a cumprir com as suas obrigações, ou seja, disposto simplesmente a cumprir ordens. Ele que, apesar de declarar ter lido Kant, aparentemente, não o tinha compreendido, visto que a filosofia moral de Kant está, de acordo com Arendt, estritamente ligada à faculdade de juízo que o homem possui e que exclui a obediência cega. Enfim, Adolf Eichmann, era simplesmente, um homem incapaz de pensar, de se colocar no lugar do outro.

O mal radical, portanto, em Arendt, não é profundo, não tem raízes. É obra de indivíduos que criaram um vazio interior, de indivíduos insensíveis ao mundo. Mal radical é, portanto, o que ela mais tarde chamará de a "banalidade do mal" (1999), uma vez que se trate sempre, no sistema totalitário, como no caso Eichmann, da destruição do pensamento, uma destruição generalizada, despercebida e, nesse sentido, banal, mas igualmente escandalosa prefigurando o aniquilamento escandaloso da vida. "Banalidade" não quer dizer, de maneira 
alguma, "inocência"; a história de Eichmann, por exemplo, não é absolutamente a de um inocente.

\section{A compreensão da novidade}

Nazismo e comunismo são, de acordo com Arendt, formas de governo inéditas e inclassificáveis dentro dos moldes da filosofia política. $\mathrm{Na}$ verdade, eles destruíram todas as alternativas sobre as quais se baseavam "as definições da essência dos governos, isto é, a alternativa entre o governo legal e o ilegal, entre o poder arbitrário e o poder legítimo" (ARENDT, 1989, p.513). Mas, será que é possível compreende-los?

Para Arendt, a resposta é positiva: quando nos confrontamos com alguma coisa que nunca havíamos visto antes e para a qual não estão a nossa disposição critérios de nenhum tipo, ela nos aconselha a recorrer a nós mesmos. Ou seja, procurar em nós mesmos alguma faculdade capaz de propor critérios novos e evidenciar a novidade em questão. Essa faculdade é para ela, a faculdade de julgar que, simplesmente, recorre à própria evidencia do julgado e, que, na sua essência, possuía apenas um único pressuposto: "a capacidade humana do discernimento, e tem muito mais a ver com a capacidade de diferenciar do que com a capacidade de ordenar e subordinar" (ARENDT, 2002, p.32).

Esse julgar, no entanto, não pode de maneira alguma significar outra coisa senão uma forma de tomar uma posição diante dos eventos particulares do mundo, refletir sobre eles sem que se disponha de antemão de um conceito ou regras universais que possam ser aplicados ao caso. Nesse sentido, tentar compreender o nazismo e o comunismo significa, fundamentalmente, emitir "juízos" sobre fatos, mesmo que não tivesse participado deles. Assim, compreender significa, no fundo, uma forma de se lidar com a realidade humana que se distingue do conhecimento cientifico e da informação correta, mas funciona como um processo complexo, sem qualquer resultado inequívoco. "Trata-se de uma atividade interminável, por meio da qual, em constante mudança e variação, aprendemos a lidar com nossa realidade, reconciliamo-nos com ela, isto é, tentamos nos inserir em casa no mundo” (ARENDT, 1993, p.39).

Compreender, portanto, vai muito além do simples relacionar os acontecimentos com determinadas leis gerais, compará-los com outros fatos análogos do passado. No caso do nazismo e do comunismo, por exemplo, se pensarmos apenas dessa forma estaremos passando ao lado daquilo que neles são essenciais, a saber, o caráter chocante e monstruoso. Compreender 
pressupõe, acima de tudo, certa dose de coragem e resistência para enfrentar a realidade nua e crua: "significa, em suma, encarar a realidade sem preconceitos e com atenção, e resistir a ela qualquer que seja, venha a ser ou possa ter sido" (ARENDT, 1989, p.21).

Para se colocar na condição de julgar, de compreender algo inédito e sem precedentes, ou seja, o nazismo e o comunismo, Arendt aconselha recorrer a uma "instância da mente" segundo ela, de extrema importância, a imaginação. Distinta do sonho e da fantasia, a imaginação possibilita ao homem "remover-se mentalmente de onde" se encontra "fisicamente colocado", para pensar "que as coisas poderiam ser diferentes do que realmente são" (ARENDT, 1973, p.15). A imaginação é entendida fundamentalmente, por ela, como a capacidade de fazer presente o ausente: quando o objeto está muito próximo, imediato, a imaginação dá o distanciamento necessário para eliminar eventuais prejuízos e parcialidades; quando o objeto está distante, ela o torna familiar. É a única bússola interior que possuímos, o que quer dizer que, sem ela, não poderíamos referenciar-nos no mundo.

\section{Considerações finais}

O nazismo e o comunismo representam para Arendt as duas faces do mesmo mal, denominado por ela de fenômeno totalitário: um tipo de regime político inédito e sem precedentes que destruiu não apenas os conceitos ocidentais tradicionais de política, reclamando assim uma nova forma de compreensão, mas a própria pluralidade humana que, para ela, é a essência da política. Nesses regimes, portanto, a política se voltou contra si mesma, ela deixou de ser o bem comum das pessoas e passou a empenhar-se com objetivos ideológicos de longo prazo, resultando na morte e na destruição de porções significativas da população. Por mais incrível que possa parecer, esses regimes foram pensados e colocados em prática por homens normais, isto é, em perfeita e boa consciência; homens que se acharam no direito de decidirem quem deve e quem não deve habitar neste planeta. Assim, compreender o nazismo e o comunismo significa preservar e possibilitar o pensamento para que ele possa interrogar qualquer "valor" e, principalmente, os "valores" de uma sociedade de fabricação e de massificação. Para isso, ele não pode se limitar à sua própria solidão, mas orientar-se em vista de seu desenvolvimento em julgamento a fim de evitar tais atrocidades no futuro. 


\section{Referências Bibliográficas}

ARENDT, H. A condição humana. Rio de Janeiro: Forense, 2009. . A dignidade da política. Rio de Janeiro: Relume Dumará, 1993. . Crises da república. São Paulo: Perspectiva, 1973.

. Eichmann em Jerusalém: um relato sobre a banalidade do mal São Paulo: Companhia das Letras, 1999.

- O que é política? Fragmentos das obras póstumas compilados por Ursula Ludz. Rio de Janeiro: Bertrand Brasil, 2002.

. Origens do totalitarismo - antissemitismo, imperialismo, totalitarismo. São Paulo: Companhia das Letras, 1989.

BAUDOUIN, Jean. Introdução à sociologia política. Lisboa: Estampa, 2000.

BAUMAN, Z. Em busca da política. Rio de Janeiro: Zahar, 2000.

BESANÇON Alain. A infelicidade do século: sobre o comunismo, o nazismo e a unicidade da shoah. Roi de Janeiro: Bertrand Brasil, 2000.

FREYER, Hans. Teoria da época atual. Rio de Janeiro: Zahar, 1965.

FURET, E. Facisme et communisme. Paris: Plon-commentaire, 1995.

RICOEUR, Paul. A crítica e a convicção. Lisboa: 70, 1995.

SARTORI, Giovanni. A politica. Brasília: UnB, 1981. 